\title{
The reason analysis of the overburden rock dumps deformation
}

\author{
Elena Ananenko ${ }^{1 *}$, and Svetlana Bakhaeva ${ }^{1}$ \\ ${ }^{1}$ T.F. Gorbachev Kuzbass State Technical University, Mining Institute, 650000 Kemerovo, the \\ Russian Federation
}

\begin{abstract}
Due to the deficiency of areas for dump facilities, mining enterprises form dumps of a large height, or locate them in places unfavorable from the stability point of view. In this regard, cases of the dump areas landslides have become more frequent. Herein there are examples of the actual deformations, causes of their occurrence, as well as preventive measures. Experience of the field surveying observations and analysis of the dump landslide causes confirm that accidents could be prevented by timely substantiating of safety criteria for the stress-strain status of the dumps and creating methodology for surveying monitoring, depending on a type of the overburden rock.
\end{abstract}

\section{Introduction}

Due to the significant growth of coal production by open-pit mining, a need for land plots for the overburden dumps placement has been increased. Kutepov Yu. I. notes that in 2016, Kuzbass developed 145 million tons of coal by open-pit mining; herewith about 1.5 billion $\mathrm{m}^{3}$ of the overburden rock was extracted from the surface and moved to dumps, which required 1,500 hectares of land to accommodate [1].

The shortage of areas for dump facilities for the majority of the mining enterprises is eliminated by increasing height of the available dumps or placing them on areas that are unfavorable from the stability point of view (ravine talweg, swampy areas). In this regard, cases of the dump area landslides have become more frequent.

\section{Materials and Methods}

One of the largest landslides took place in April 2015 on the outer dump of the mine ' $Z$ ' (Fig. 1).

A dump of $122 \mathrm{~m}$ height located in ravine talweg was filled with bedrock: mainly siltstone with admixture of sandstone and argillites. In the lower part of the dump, loams and clays of the solid to fluid-plastic consistency were stored.

Thus, 7.5 million $\mathrm{m}^{3}$ of the dump mass tuned out outside the outer dump. Deformation development could be characterized as follows: initiating event took place in the area of the ravine talweg (Fig. 2). The deformation provoked a larger-scale violation of stability along

\footnotetext{
* Corresponding author: chernykhev@,kuzstu.ru
} 
the ravine slope that subsequently affected the dump mass integrity of the southern edge part of the dump. When the landslide mass reached the flooded area along the highway, the body of the landslide changed the north-west movement vector and began to spread out along the path of least resistance in the west and south-west directions. Having met a natural barrier in a form of the western slope of the Kyrgay river valley, where there was some compensation for landslide pressure, and further damping of kinetic energy, the movement of the dump mass followed in the southern direction along the river.

In the landslide influence zone there were $110 \mathrm{~kW}$ and $10 \mathrm{~kW}$ power lines that disrupted operation of five mining enterprises, including mines. The technological public highway and railway tracks were filled up with dump rocks, the Kyrgay riverbed has been blocked for 4 days before the spring flood.

As a result of the accident, operations at a number of enterprises were halted, the shipment of the extracted coal was disrupted, large industrial enterprises has power outages, a huge territory was flooded, tanks at the gas station were deformed, as a result, hazardous substances leaked into the Kyrgay river.

The main deformation reason is the overlap of the atmospheric precipitation runoff from the dump surface by the road and railway embankments that led to the formation of the man-made water-bearing horizon in the dump body, and decrease in the strength characteristics of the rocks in the dump lower part.

Deformation mechanism: rotational flat shear with heave.

Operation of the external overburden dump of the mine ' $R$ ' has been carried out since 2014. Territory designated for a dump is located on the watershed and is a deeply dissected valley with alternating ravines and dumps. Ravine talweg are swampy.

Bedrock and Quaternary Period deposits were stored into the external dump in the percent ratio of $80 / 20 \%$.

The dump forming had been carried out after the engineering preparation of the foundation that included construction of drainage ditches and trenches, removal of weak rocks from the dump foundation (locally) and their replacement with bedrock of low soaking capacity.

As a result of the dump deformation in September 2017, two sliding tongues were formed - the northern and southern (Fig. 3). The southern part of the landslide is a deformation along the ravine talweg; the sliding rocks are at the angle close to the angle of the foundation inclination $\left(3-5^{\circ}\right)$. The northern tongue of the landslide is the sliding rocks of the dump mass from the watershed on a slope with a slope of $3^{\circ}$.

In the area of the landslide impact there were technological roads leading to the external dump and mining excavation, as well as the technological road of the adjacent mine, because of which the movement at the enterprises was paralyzed.

The main reasons for the dump deformation are the dump construction technology violation and access roads forming to the dump without taking into consideration the provision of free ground water drainage through the roadbed that led to creation of a manmade water-bearing horizon in the dump body.

Deformation mechanism: sediment, shear along the weak layer with heave.

\section{Results and Discussion}

Practice of the dump operation and inquiry of the landslide causes [2-4] shows (Fig. 4) that $32 \%$ cases occurred during forming of the external dumps on weak foundation, $23 \%$ - in presence of ravines, watersheds on the site for a dump and inclined foundation, $25 \%$ - due to incorrect technology for the foundation preparing and order of the dumps forming, $15 \%$ due to hydrogeological factors, creation of the man-made water-bearing horizons in the 
foundation or dump body, and 5\% - others such as: natural and man-made seismicity, equipment loads exceeding the rocks load-bearing capacity.

The dumps are under influence of the loads and impacts (Fig. 5) that, in turn, with a various combination of them, can lead to a change in the stress-strain status and provoke the structure deformation.

The ratio of the holding forces $F_{\text {hld }}$ acting on the most stressed sliding surface to the shear forces $F_{\text {shear }}$ determines the structure stability.

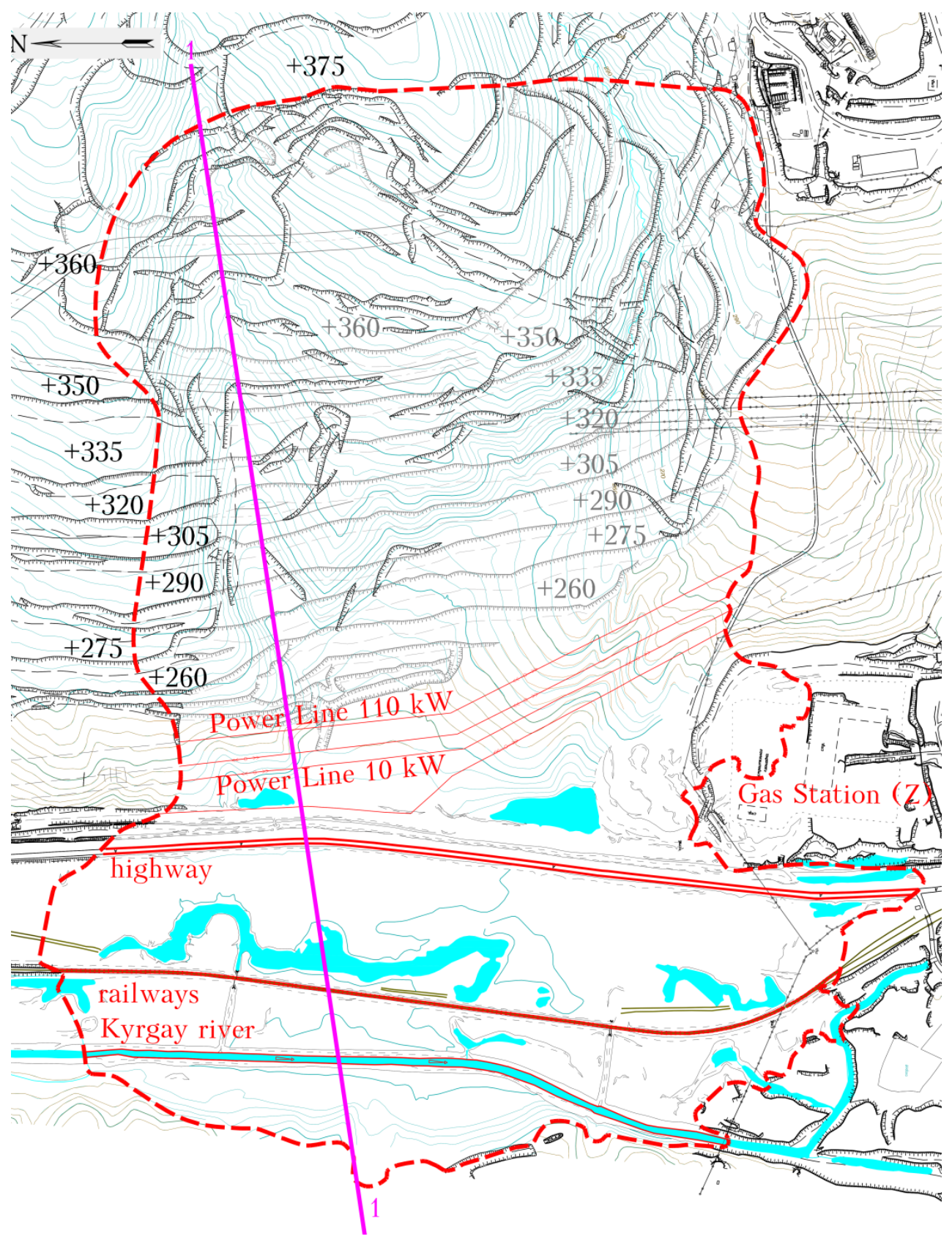

Fig. 1. Map plan with landslide application of the external dump at the mine ' $Z$ ' 


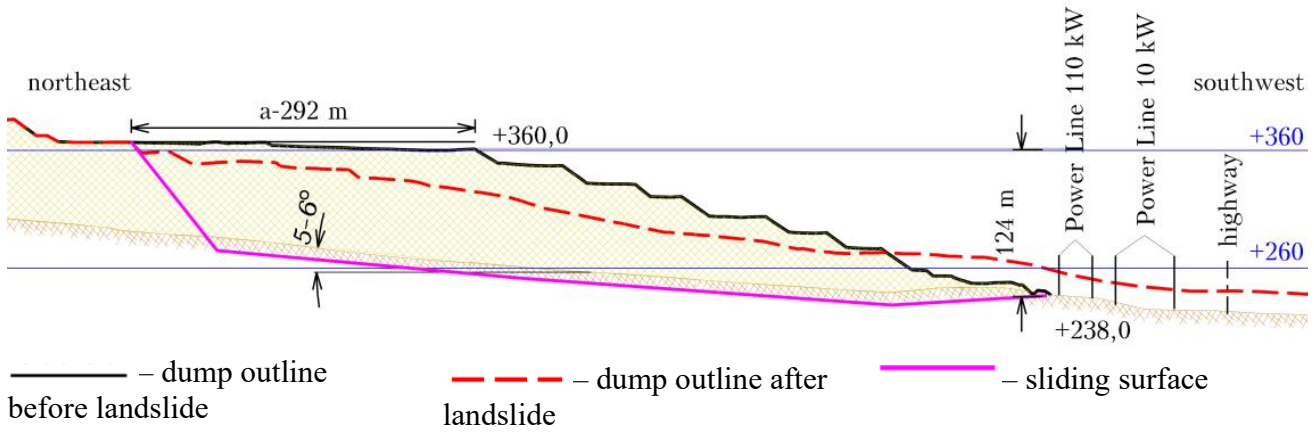

Fig. 2. Cross-section 1-1 on landslide of the external dump at the mine ' $Z$ '

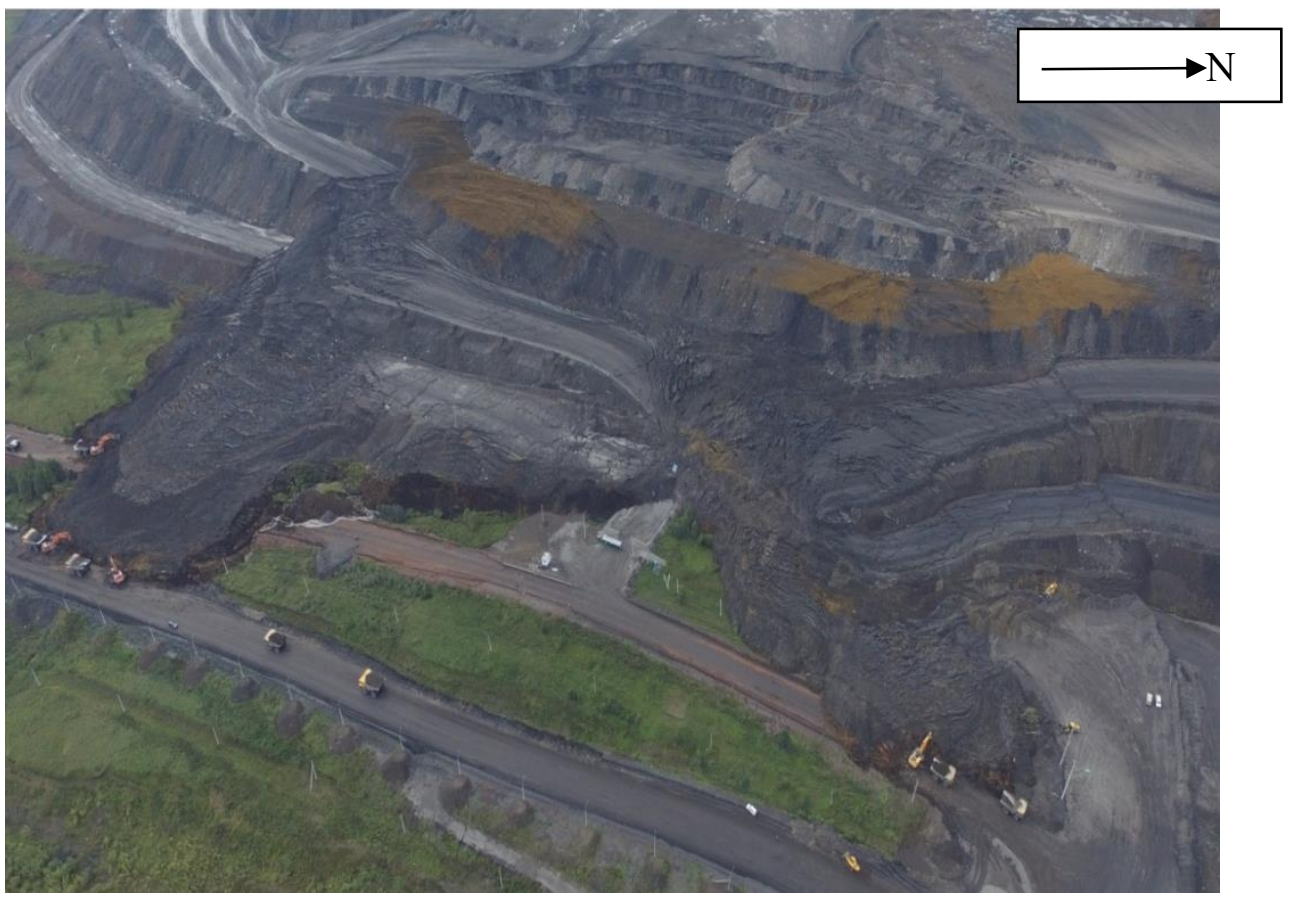

Fig. 3. Landslide of the External dump at the mine 'R' (photo from a quad-copter)

The constant load from the structure's own weight is the force of the dump rocks weight of the possible collapse prism $\mathrm{P}$, is directed vertically downwards. The weight force of the dump rocks is divided into tangent $\mathrm{T}$ and normal $\mathrm{N}$ components (Table.1, condition 7 ). The shear forces $F_{\text {shear }}$ act until the inclination angle of the sliding surface $\alpha \mathrm{i}$ reaches the value equal to the angle of internal friction of the rocks $\varphi$ at the point $O$ (Table 1.3, condition 5). The holding forces $F_{\text {hld }}$ start working when the inclination angle of the sliding surface $\alpha \mathrm{i}$ is less than the angle of the rocks internal friction $\varphi$. When the holding and shear forces are equal, $F_{\text {hld }}=\mathrm{F}_{\text {shear, }}$, the dump gets a state of extreme equilibrium. With a slight increase in the shear forces (for example, an increase in the dump height), there will be violations of the structure stability. 


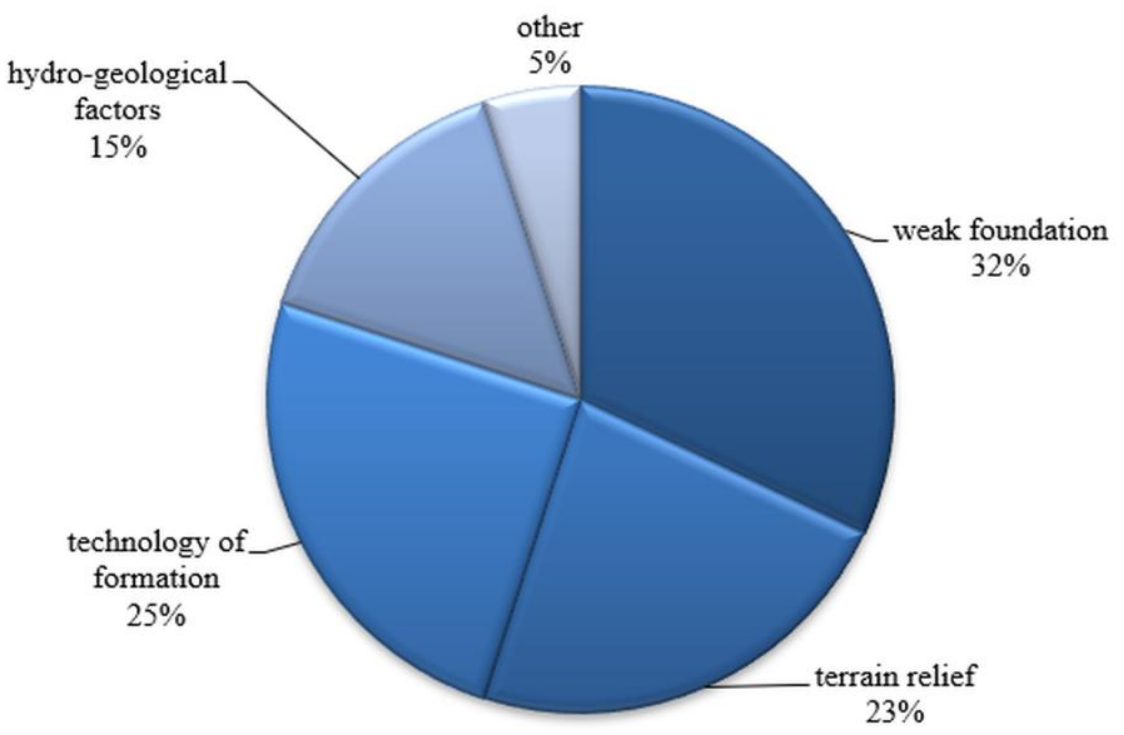

Fig. 4. Causes of landslides on dumps

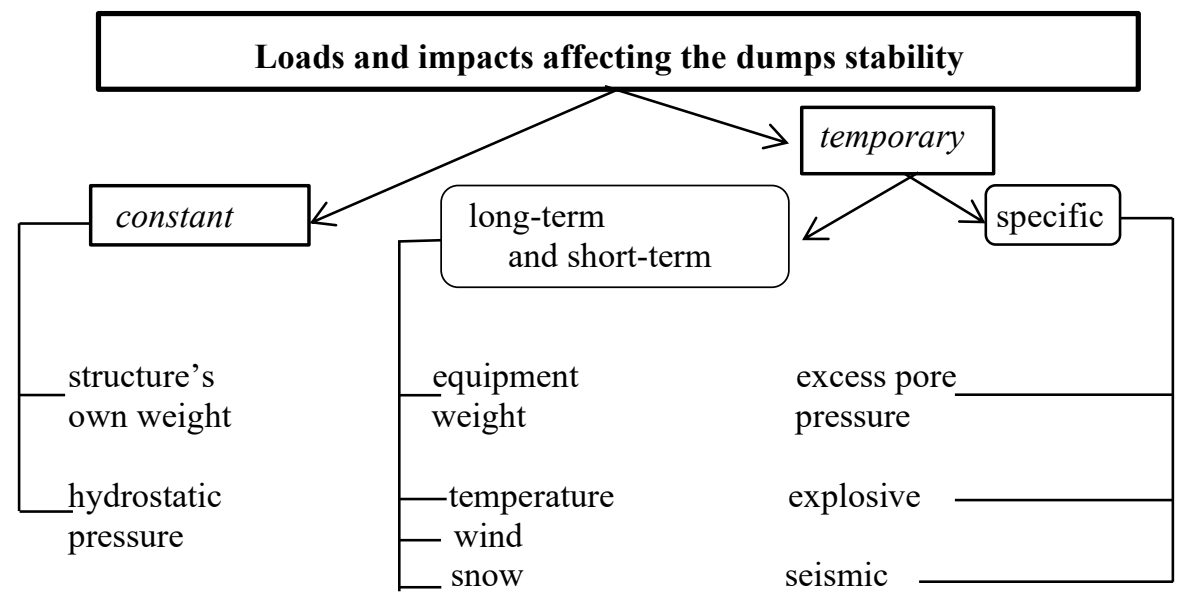

Fig. 5. Loads and impacts on dump

Technological or mining equipment placed on the dump (excavator, dump truck or conveyor) creates static and dynamic pressure. It is proved that at the equipment vibrations the internal friction angle of the soil does not change, however due to the reduction of compressive or increasing shear stresses during the period of the dynamic load, the shear resistance of the rocks decreases. As a rule, the dynamic load of the $\mathrm{P}_{\text {equipment }}$ is several times greater than the static load (Table 1, Table 2).

Hydrostatic weighing and hydrodynamic pressure are vector values (Table 1, condition 8). Hydrostatic weighing, manifested by the Archimedean forces $\left(F_{\text {arch }}\right)$, is directed vertically upwards (in the direction opposite to the direction of the gravitational forces). Hydrodynamic pressure, being a volumetric force, is oriented at each point of the mass in the direction of the pressure gradient. That is why, to evaluate the effect of hydrodynamic 
forces, it is necessary to construct current lines, the orientation of which depends on the filtration inhomogeneity of the mass and the head distribution at fixed boundaries [5].

The total effect of the hydraulic weighing and hydrodynamic pressure are manifested as hydrostatic pressure distributed over the sliding surface, along normal to it and changing only the normal component; hydrostatic pressure does not significantly affect the tangential component.

The deformability of the dumps and their foundations should be evaluated within the effective stresses having formed by increasing the dump height. The value of the effective stresses is determined taking into account the hydrostatic weighing of the dump rocks and its foundation. With this premise, compressible rocks should be considered as such, where under the action of expected or realized effective stresses, an additional pore (excess over hydrostatic) pressure occurs [5] (Table 1, conl.4). Compressible rocks are water-saturated clays and loams.

Seismic impact $F_{\text {seismic }}$ is a ground vibration motion caused by natural (earthquake) factors that result in the shear of the structure. The seismic force acts in the center of the soil mass gravity and is directed horizontally toward the shift (Table 1, condition. 6). Manmade seismic impacts (explosions) act equally to the seismic force of the natural origin, but have the opposite direction (Table 1, condition.1).

Climatic factors have a significant impact on the dump stability. The amount of precipitation, thickness of the snow cover and duration of its melting affect the feeding of the water-bearing horizons (Table 1, Table 3). Prolonged rains are a common cause of the dump deformations. On the mines of Kuzbass, the activation of the dump landslides happens during the period of snowmelt (April - May) and autumn showers (September) [6].

Temperature influence with constant cycles of freezing and thawing, depth of rock seasonal freezing, velocity and direction of wind, changing in time and space - all these affect the intensity and degree of weathering, provide formation of crumbling and destruction of the sites between the dump slopes. Negative temperature and presence of soil moisture cause frost heave, and then setting down during thawing [9].

Apart from the mentioned impacts on the dump hereinabove, special attention should be paid to the choice of the dump site. Should there are soft-plastic or fluid-plastic soils in the foundation of the dump, the risk for the structure deformation increases, when the dump height does not correspond to the physical and mechanical properties of the foundation rocks due to decrease in shear resistance at moistening of the foundation rocks.

An equally imperative factor is the technology of the dump forming that depends on a type of the inclined foundation (natural slope of the terrain of the earth's surface, the ravine talweg or soil of the inclined formation [7]. It should be understood that at placing the dump in the ravine talweg, it is necessary to be guided by the parameters of the dump, which are determined by the rocks physical and mechanical properties in the ravine part, as a rule, these are watered rocks with low strength characteristics.

Uneven placement of the dump rocks of various strengths in a loosened state and deposing into the lower layers of the dump with weak rocks, as well as non-compliance with the sequence and intensity of the piling of the dump rocks are no less significant factors affecting stability of the dumps.

Systematization of the deformation processes of the overburden dumps considering foundation and the rocks displacement mechanism as per M. E. Pevzner [8] are given in Table 1. 
Table 1. Schemes of deformation of dumps on strong and weak foundations

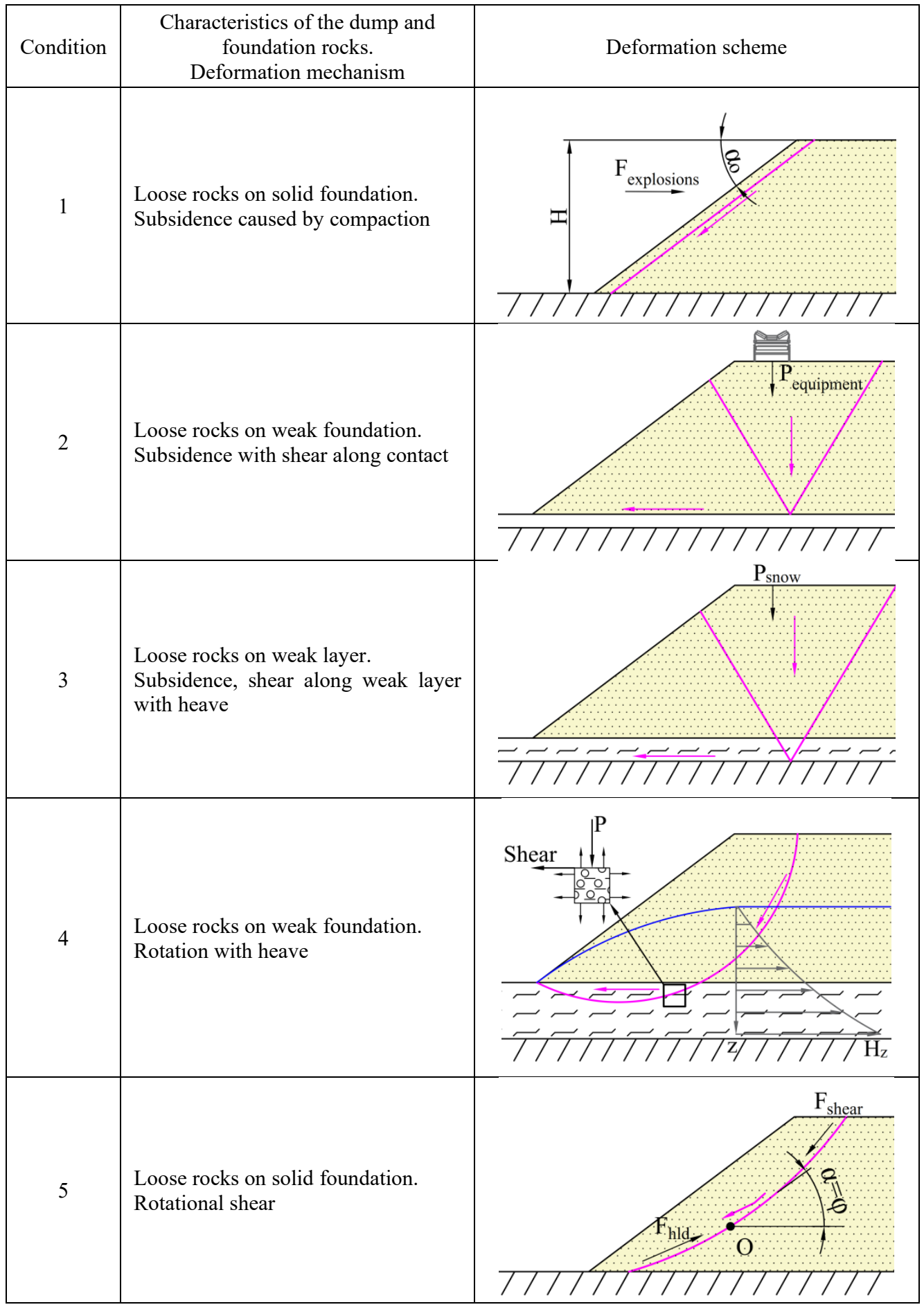




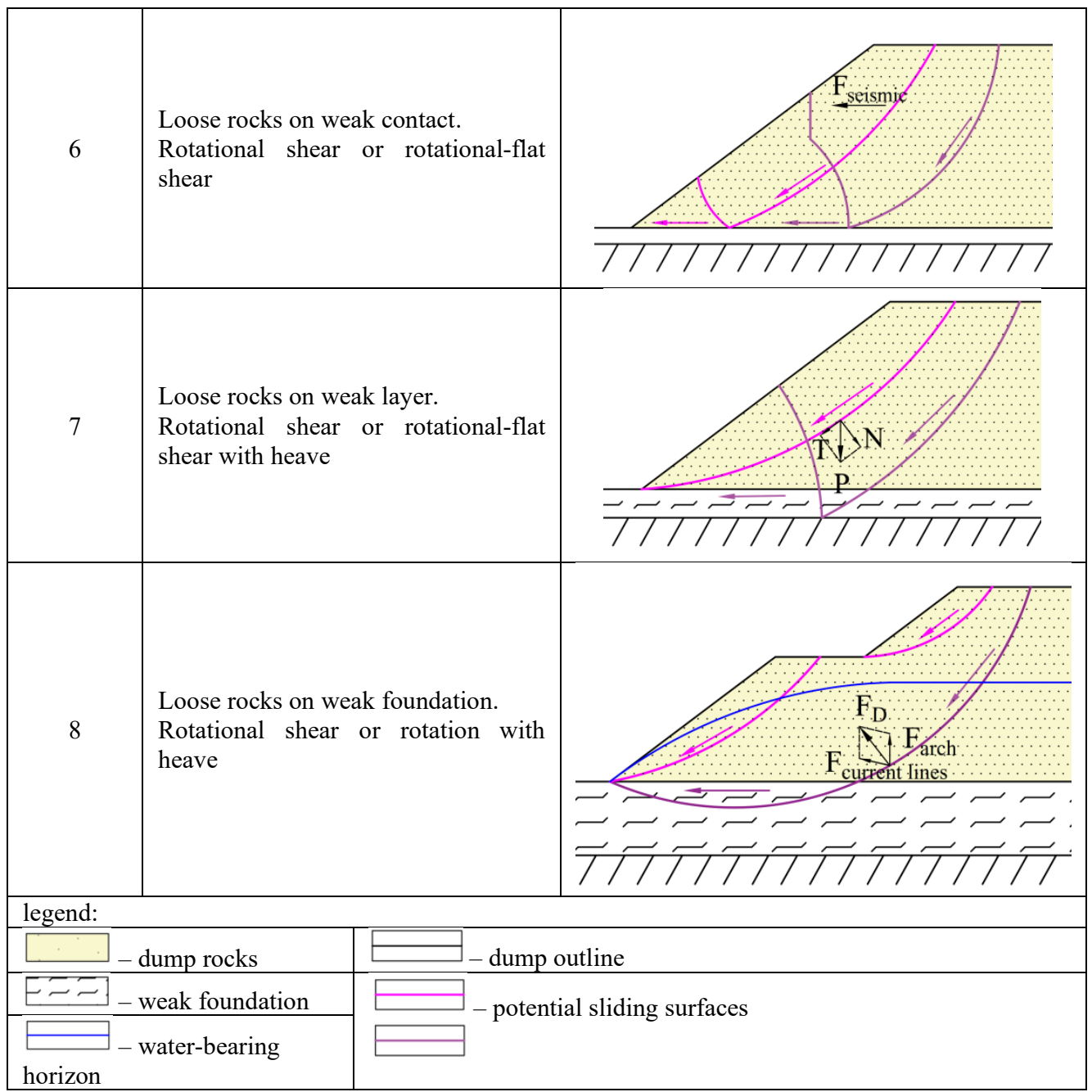

\section{Conclusions}

Experience of the dump operation, visual and instrumental surveying observations, study of the conditions and causes of the dump deformation shows that the stability violation is associated with the action of the mining factors (incorrect order of formation, exceeding the tier critical height), the activation of deformations occurs, as a rule, under the influence of atmospheric precipitation, leading to saturation of the dump rocks and foundation with water and decrease in their strength characteristics [7]. Timely detection of the destructive processes and signs of the dump deformation is possible by creating of the mine survey monitoring system, establishing of the qualitative and quantitative safety criteria.

Development and implementation of the methodology for the survey monitoring of the overburden dumps will reduce risk of the dumps deformations. 


\section{References}

1. Yu. I. Kutepov, A. D. Vasilyeva, Engineering-and-Geological Conditions for External Dump Formation on the Kuzbass Mines, GIAB, 10, 122 (2017)

2. E. V. Ananenko, S. P. Bahaeva, Geo-mechanical Substantiation of the Stable Embankment along the Ravine Talweg, "Mine Surveying and Subsurface and Mineral Management", 10, 35 (2020)

3. S. P. Bahaeva, E. V. Ananenko. Study of the Conditions for Construction of the Embankments in the Deposit Ledger-wall, GIAB, 9, 55 (2020)

4. S. Bakhaeva, E. Chernykh, Study of the Conditions for Construction of the Haulage Berm in the Deposit Ledger-wall, E3S Web of Conferences 105, 01034 (2019) IVth International Innovative Mining Symposium (2019)

5. Guidelines for Methods of Hydro-and-geo-mechanical Substantiation of the Optimal Parameters of the Hydraulic Dumps and Dumps on Weak Foundations. Part 1. Study of the hydro-geo-mechanical conditions for the construction, operation and remediation of dump structures. L.: VNIMI (1989)

6. S. P. Bahaeva. Calculation of Slope Stability at the Open geo-technologies, FSBEI of HE T. F. Gorbachev KuzSTU (2011)

7. S. P. Bahaeva, E. N. Zavorina, Forecast of the Stability of the Rock Dumps at Coal, KuzSTU, SF of JSC VNIMI (Nauka Publishing House, Novosibirsk, 2014)

8. K. N. Trubetskoy, Opencast Mining: a reference book (Mining Bureau, Moscow, 1994)

9. J. Read, P. Stacey, Guidelines for open pit slope design (2010) 